(c) American Dairy Science Association, 2003.

\title{
Maternal and Fetal Inbreeding Depression for 70-Day Nonreturn and Calving Rate in Holsteins and Jerseys
}

\author{
B. G. Cassell, V. Adamec, ${ }^{1}$ and R. E. Pearson \\ Department of Dairy Science \\ Virginia Polytechnic Institute and State University \\ Blacksburg 24061-0315
}

\begin{abstract}
Inbreeding depression for 70 -d nonreturn rate was estimated in 50,613 Holstein and 47,673 Jersey cows with five-generation pedigrees using an animal model. Heritabilities of 70-d nonreturn rate were very low for both breeds ( 1 to $2 \%$ ). Maternal inbreeding depression was small (3\% reduction for 10\% inbreeding) and significant only for Jerseys. Fetal and maternal inbreeding depression was not significant for individual parities in Holsteins, but maternal inbreeding depression was significant in first parity only in Jerseys. Maternal and fetal inbreeding depression of calving rate (verified by a subsequent calving) was estimated on separate datasets by parity from 13,229 to 26,876 Holstein and 7374 to 11,742 Jersey cows. First-parity estimates for heritability of calving rate were $1 \%$ or less, whereas estimates for later parities varied from 1 to $6 \%$. Significant inbreeding depression in first-parity Holsteins reduced calving rate by $4 \%$ per $10 \%$ maternal or fetal inbreeding, but effects, while undesirable, were not consistently significant in other parities. In Jerseys, maternal inbreeding significantly reduced calving rate by $6 \%$ per $10 \%$ inbreeding in first parity, and was undesirable but not significant for second through fourth parities. Fetal inbreeding depression was not significant in Jerseys. Maternal inbreeding depression of 70-d nonreturn and calving rate was small, undesirable, but not consistently significant across breeds and parities. The cumulative economic impact of maternal or fetal inbreeding on lifetime reproductive performance of Holstein or Jersey cows would be more dramatic than results for a single breeding.
\end{abstract}

(Key words: inbreeding, fertility, Holstein, Jersey)

Abbreviation key: 70d NR = 70-d nonreturn, $\mathbf{C R}=$ calving rate, ABTK = Animal Breeders Tool Kit, AIPL = Animal Improvement Programs Laboratory.

Received March 18, 2003.

Accepted April 28, 2003.

Corresponding author: B. G. Cassell; e-mail: bcassell@vt.edu.

${ }^{1}$ Present location: University of Brno, Czech Republic.

\section{INTRODUCTION}

Dairy cattle in the United States have been selected for rather narrowly defined selection objectives, placing them at increased risk for detrimental effects of inbreeding (Notter, 1999). Further, Thompson et al. (2000a, 2000b) reported geometric increases in average inbreeding in Holstein and Jersey populations between 1970 and 1998. An expected consequence of increased inbreeding is decreased fitness, including survival, health, and vigor, and reproductive efficiency. Reproductive performance of dairy cattle has particular economic importance as an essential process in production of replacements and as the initiator of milk production.

Smith et al. (1998) reported a decrease of $13.1 \mathrm{~d}$ in length of productive life (defined as the period from birth of first calf through culling date from the herd) for each $1 \%$ increase in inbreeding in registered Holsteins. The same study reported a loss of $\$ 22$ to $\$ 24$ lifetime net income per $1 \%$ increase in inbreeding. These are cumulative effects of many traits, production, health, and vigor, reproductive processes among them. Smith et al. (1998) also reported an extension of first calving interval by $0.26 \mathrm{~d}$ per $1 \%$ increase in inbreeding, a more specific measure of the effects of inbreeding on reproductive performance. Thompson et al. (2000a, $2000 \mathrm{~b}$ ) reported increases in age at calving for Holsteins and Jerseys when inbreeding exceeded $10 \%$, but not for smaller amounts of inbreeding. Both of the reports by Thompson et al. (2000a, 2000b) showed a decrease in lactation length by 2 to $8 \mathrm{~d}$ in Holsteins when inbreeding exceeded $10 \%$ and by 3 to $5 \mathrm{~d}$ when inbreeding exceeded $5 \%$ in Jerseys. The authors concluded that the biggest expense of inbreeding was a reduction in survival.

The work of Smith et al. (1998) and Thompson et al. (2000a, 2000b) addressed production, survival, and lifetime performance rather than individual reproductive events. Hoeschele (1991) noted that fertility included paternal, maternal, and filial components, and both genetic and permanent environmental effects. She reported an increase in days open of $0.13 \mathrm{~d} / 1 \%$ increase in inbreeding in Holsteins and an extension of service 
period (days from first to last breeding) of $0.10 \mathrm{~d} / 1 \%$ increase in inbreeding. Pulkkinen et al. (1997) examined the effects of both maternal and fetal inbreeding in a study of multiphasic logistic functions of sequential breeding records. This preliminary work found a confounding between maternal and fetal inbreeding such that greater inbreeding in dams was associated with less inbreeding in the fetus. Inbreeding in the dam, but not the fetus reduced 56-d nonreturn to service. Inbreeding in the fetus, but not the dam reduced the probability of a birth given a nonreturn to service. Inbreeding in the dam appeared to affect embryo survival in early gestation, whereas inbreeding of the fetus affected its survival at later stages.

Estimates of effects of maternal inbreeding on fertility traits are not widely available in the literature, and the role of inbreeding in the fetus is even less well known. Phenotypes for fertility are not normally distributed but are either discontinuous (nonreturn data, calving rates) or continuous with substantial skewedness (Hoeschele, 1991). Efforts have been made to address these challenges (i.e., threshold models with Gibbs sampling, Weigel and Rekaya, 2000), but the methods are computationally tedious and problems do occur with small contemporary groups containing all successes or failures. The purpose of our study was to estimate maternal and fetal inbreeding depression on fertility in Holsteins and Jerseys. The traits studied were 70-d nonreturn to service (70d NR) and calving rate (CR), where success is verified by a subsequent calving.

\section{MATERIALS AND METHODS}

Data for this study were provided by DRMS in Raleigh (NC) and included first services reported through DHI for 1995 through 1998. Initial data included $1,780,281$ first services on 1,213,475 Holstein cows and 115,344 first services on 77,379 Jersey cows across all parities. Data edits are detailed in a companion study (Cassell et al., 2003). The Holstein file consisted of $36.3 \%$ registered and $63.7 \%$ grade cows. Many pedigrees were only partially complete in grade Holsteins. On the basis of Cassell et al. (2003), we restricted data reported in this study to registered Holsteins where complete five-generation pedigrees were available on almost all cows. We used all available Jersey data, which were $86 \%$ registered, because pedigrees were substantially complete for five generations on both registered and grade cows in that breed. Inseminations were restricted to services to bulls in AI service and only services to cows in parities 1 to 4 were retained.

Pedigree data were obtained from the Animal Improvement Programs Laboratory (AIPL), USDA, Belts- ville, Maryland. The AIPL files include estimates of inbreeding calculated by a method that replaces missing ancestors with average relationships between relatives of similar approximate ages (VanRaden, 1992). We constructed five-generation pedigrees from AIPL pedigree files, and estimated inbreeding directly from the pedigrees using the traditional procedures of Golden et al. (1995) in the Animal Breeders Tool Kit (ABTK). These estimates were used throughout the study rather than the estimates from AIPL, where average relationships replaced those few ancestors that were missing. This approach differs from Cassell et al. (2003), where AIPL and ABTK inbreeding estimates were compared. Fetal inbreeding was estimated by combining pedigrees of service sire with the pedigree of each cow bred. A base of 1960 was used for all pedigrees.

Two measures of conception were used: $70 \mathrm{~d}$ NR and CR were scored as binary traits. If a cow returned to service by the report of a subsequent service through DHI within $70 \mathrm{~d}$ of first service, both $70 \mathrm{~d}$ NR and CR were recorded as zero. If a subsequent service was reported after $70 \mathrm{~d}$ but prior to the next parturition for any reason, $70 \mathrm{~d} \mathrm{NR}$ was recorded as 1 . Calving rate was coded as 1 only if the cow initiated a subsequent lactation as a result of the first service as determined by an acceptable gestation interval. If CR was $1,70 \mathrm{~d}$ NR was also 1 , but CR could be 0 , while $70 \mathrm{~d}$ NR was 1 if the cow was inseminated a second time more than $70 \mathrm{~d}$ after first service. We restricted CR to first services in 1995 and 1996 to allow opportunity for the cow to deliver a calf to the reported first service.

Registered Holstein files were too large to include all animals in analysis. We selected a random sample of complete herd data where five or more cows were bred in all herd-year-seasons and restricted the final dataset to 70,000 to 80,000 records or approximately 50,000 cows. Jersey data were similarly restricted to herds with five or more cows per herd-year-season of breeding, but all qualifying herds were used. As CR was estimated only from cows bred in 1995 and 1996, the procedure was repeated for each breed to create four separate files for 70d NR and CR in Holsteins and Jerseys. Analysis by parities 1 to 4 was based on cows included in these four datasets.

Data were analyzed using the following animal model and the derivative-free procedure (MTDFREML) described by Boldman et al. (1995). The model used, in matrix form, is as follows:

$$
\mathrm{Y}=\mathrm{Xb}+\mathrm{Zu}+\mathrm{Wp}+\mathrm{e},
$$

where $\mathrm{Y}$ is a vector of observations, $\mathrm{X}, \mathrm{Z}$, and $\mathrm{W}$ are incidence matrices associating vectors of fixed effects and covariates $(b)$, additive genetic effects $(u)$, and per- 
Table 1. Effects of inbreeding in the cow on 70-d nonreturn to service in Jerseys and Holsteins and of inbreeding in the fetus in Holsteins using a repeatability model.

\begin{tabular}{lccc}
\hline & & \multicolumn{2}{c}{ Holsteins } \\
\cline { 3 - 4 } Parameter & Jerseys $^{1}$ & $\begin{array}{l}\text { Inbreeding in } \\
\text { the cow }\end{array}$ & $\begin{array}{l}\text { Inbreeding in } \\
\text { the fetus }\end{array}$ \\
\hline Number of cows & 47673 & 50613 & \\
Number of records & 75357 & 73017 & 4.51 \\
Average F(x) (\%) & 4.49 & 3.67 & 2.13 \\
Standard deviation $\mathrm{F}(\mathrm{x})$ & 2.85 & 2.37 & \\
70-d nonreturn to service & & & \\
Mean & 0.56 & 0.52 & -0.001 \\
Standard deviation & 0.49 & -0.002 & 0.001 \\
Inbreeding depression/1\% $\mathrm{F}(\mathrm{x})$ & -0.003 & 0.001 & 0.181 \\
Standard error & 0.001 & 0.065 & 0.01 \\
$P$-value & 0.001 & 0.01 & \\
Heritability & 0.02 & &
\end{tabular}

${ }^{1}$ Inbreeding in the cow.

manent environmental effects (p) with the observations, and e is a vector of residual errors. The model is further specified as an animal model for repeated records on single traits.

$$
\begin{gathered}
\mathrm{Y}_{\mathrm{ijklm}}=\mathrm{HYS}_{\mathrm{i}}+\mathrm{P}_{\mathrm{j}}+\mathrm{SSC}_{\mathrm{k}}+\beta \mathrm{F}_{1}+\mathrm{AN}_{\mathrm{l}} \\
+\mathrm{PE}_{\mathrm{l}}+\mathrm{E}_{\mathrm{ijklm}}
\end{gathered}
$$

where

$\mathrm{Y}_{\mathrm{ijklm}}=$ conception outcome of $70 \mathrm{~d} \mathrm{NR}$ or CR;

$\mathrm{HYS}_{\mathrm{i}}=$ random effect of the ith herd, year, and season (Dec-Mar, Apr-Jul, Aug-Nov) of breeding;

$\mathrm{P}_{\mathrm{j}}=$ fixed effect of parities 1 to 4 ;

$\mathrm{SSC}_{\mathrm{k}}=$ fixed effect of the kth service sire class;

$\beta \mathrm{F}_{1}=$ linear effect of maternal or fetal inbreeding in cow 1 or her fetus;

$\mathrm{AN}_{\mathrm{l}}=$ random effect of the lth cow being bred;

$\mathrm{PE}_{1}=$ random permanent environmental effect for the lth cow; and

$\mathrm{E}_{\mathrm{ijk} \mathrm{km}}=$ random residual error for the mth record on cow 1 .

Service sire class specifies whether the service sire was in sampling or a proven bull at the time of use. Holstein bulls less than $1700 \mathrm{~d}$ and Jersey bulls less than $1625 \mathrm{~d}$ of age at time of service were considered to be in progeny testing programs. This effect was included to account for the practice of some herds to use young sire semen to inseminate cows that may not be in estrus at time of insemination (John Clay, personal communication). Some bulls would have services both as young sires and proven bulls across the $4 \mathrm{yr}$ of data examined. We included three generations of pedigree information on the cow being bred in the relationship matrix for MTDFREML analysis. When fetal inbreeding was included as a covariate, the relationship matrix was still based on the dam's pedigree. We chose to use MTDFREML for analysis of these binary traits on the basis of findings by Weigel and Rekaya (2000), where threshold models with Gibbs sampling were compared to MTDFREML procedures. Variance component estimates were slightly larger from threshold models, but were estimated with considerable difficulty due to "extreme subclass" problems where all cows bred in a herdyear-season either conceived or failed to conceive. The above model was modified for use with data from individual parities by eliminating parity and permanent environmental effects. We examined parities separately because of evidence in Thompson et al. (2000a, $2000 \mathrm{~b}$ ) that effects of inbreeding tended to be greater in younger animals for some traits. Some caution should be exercised in evaluating analysis by parity, as cows in advanced parities would have been those that reproduced successfully earlier in life.

\section{RESULTS AND DISCUSSION}

Effects of maternal inbreeding in Jerseys and Holsteins and fetal inbreeding in Holsteins on $70 \mathrm{~d}$ NR across parities are in Table 1 . These analyses are based on the repeatability model [1] that included effects of parity and permanent environment. Fetal inbreeding on 70d NR in Jerseys was not included in this study, though fetal inbreeding effects on CR are reported later. Results are from 50,613 Holstein cows averaging 3.67\% inbreeding bred to bulls that produced $4.51 \%$ inbreeding in the fetus and from 47,673 Jersey cows with an average inbreeding of $4.49 \%$. For comparison, Holstein cows born in 1994 and 1995 averaged 3.5 and 3.7\% inbreeding, while Jerseys born in 1995 and 1996 averaged 4.8 and $5.1 \%$ inbreeding, respectively (Animal Improvement Programs Laboratory, 2003). Average fetal inbreeding of $4.51 \%$ in Holsteins is similar to average 
Table 2. Effects of inbreeding in Holstein cows on 70-d nonreturn to service by parity.

\begin{tabular}{lcccc}
\hline & $\begin{array}{l}\text { First } \\
\text { lactation }\end{array}$ & $\begin{array}{l}\text { Second } \\
\text { lactation }\end{array}$ & $\begin{array}{l}\text { Third } \\
\text { lactation }\end{array}$ & $\begin{array}{l}\text { Fourth } \\
\text { lactation }\end{array}$ \\
\hline Number of records (cows) & 24625 & 19983 & 13142 & 15267 \\
Average F(x) & 4.10 & 3.82 & 3.53 & 2.89 \\
Standard deviation F(x) & 2.32 & 2.36 & 2.34 & 2.29 \\
70-d nonreturn to service & & & & \\
Mean & 0.55 & 0.52 & 0.52 & 0.49 \\
Standard deviation & 0.49 & 0.49 & 0.49 & 0.50 \\
Inbreeding depression/1\% F(x) & -0.001 & -0.002 & -0.001 & -0.003 \\
Standard error & 0.001 & 0.002 & 0.002 & 0.001 \\
$P$-value & 0.293 & 0.141 & 0.499 & 0.149 \\
Heritability & 0.01 & 0.02 & 0.01 & 0.02 \\
\hline
\end{tabular}

inbreeding for Holstein females born in 2000. These data were from inseminations performed from 1995 through 1998, suggesting that the Holstein cows in particular were slightly more inbred than cows of the same breed and birth year in USDA files. Requiring the Holsteins to be registered, thus increasing pedigree information available relative to all cows may explain the slight discrepancy.

Average 70d NR was higher in Jerseys (0.56) than in Holsteins (0.52). Both values were higher than most phenotypic means for 60 - or 90 -d nonreturn rates from Weigel and Rekaya (2000), who reported values from 0.30 to 0.57 for Minnesota and California herds. In our data, all terms in model [1] explained 6 to $7 \%$ of variation in $70 \mathrm{~d}$ NR in Holsteins and 7 to $10 \%$ in Jerseys. Weigel and Rekaya accounted for about $8 \%$ of variance in $60 \mathrm{~d}$ or $90 \mathrm{~d} \mathrm{NR}$ with a similar linear model, and reported heritabilities of 1.4 to $3.1 \%$ for female fertility measures. Our heritabilities of 1 or $2 \%$, also showed additive genetic variance accounted for a small portion of total phenotypic variation in $70 \mathrm{~d}$ NR.

Inbreeding depression for 70d NR from the repeatability model was small, undesirable, and nonsignificant for Holsteins for either maternal or fetal inbreeding. Maternal inbreeding depression in Jerseys was significant, and showed that a Jersey cow with $10 \%$ inbreeding would be expected to have about 3\% lower 70d NR than a noninbred Jersey cow. These apparent breed differences may reflect differences in data quality rather than differences in gene action in Holsteins and Jerseys. The effects are small and difficult to measure. On the other hand, differences in traits such as estrus expression may improve the accuracy of estrus detection in Jerseys. If so, phenotypic variance in $70 \mathrm{~d}$ NR might be reduced relative to genetic variance in Jerseys, enabling us to detect statistically significant inbreeding depression in one breed but not the other. Breed differences in estrus expression through electronic monitoring are documented (Nebel et al., 2002).

Tables 2 and 3 include the same cows as Table 1, but separated by parity. The model used for Tables 2 and 3 omitted parity and permanent environment from [1]. Table 2 shows that inbreeding in Holsteins was higher in first-parity cows, the most recently born, and lowest in the fourth-parity cows. The fertility measure, $70 \mathrm{~d}$ NR, also was lower for cows in later parities. Estimates of heritability were small in all parities. Maternal inbreeding depression was always undesirable in Holsteins but was not statistically significant in any parity. Jersey results in Table 3 showed a similar decline in average inbreeding and in fertility for older cows. Maternal inbreeding depression was significant in first parity and was more extreme, a 5\% loss in $70 \mathrm{~d}$ NR for $10 \%$ inbreeding, than the estimate of $3 \%$ per $10 \%$

Table 3. Effects of inbreeding in Jersey cows on 70-d nonreturn to service by parity.

\begin{tabular}{lcccc}
\hline & $\begin{array}{l}\text { First } \\
\text { lactation }\end{array}$ & $\begin{array}{l}\text { Second } \\
\text { lactation }\end{array}$ & $\begin{array}{l}\text { Third } \\
\text { lactation }\end{array}$ & $\begin{array}{l}\text { Fourth } \\
\text { lactation }\end{array}$ \\
\hline Number of records (cows) & 21506 & 18026 & 13677 & 22148 \\
Average F(x) & 5.11 & 4.83 & 4.45 & 3.63 \\
Standard deviation F(x) & 2.91 & 2.85 & 2.70 & 2.68 \\
70-d nonreturn to service & & & & 0.56 \\
Mean & 0.58 & 0.56 & 0.49 & 0.53 \\
Standard deviation & 0.49 & 0.49 & -0.001 & -0.003 \\
Inbreeding depression/1\% F(x) & -0.005 & -0.001 & 0.002 & 0.001 \\
Standard error & 0.001 & 0.001 & 0.393 & 0.024 \\
P-value & $<0.001$ & 0.274 & 0.01 & 0.04 \\
Heritability & 0.01 & 0.01 & & \\
\hline
\end{tabular}


Table 4. Effects of inbreeding in Holstein cows or in the fetus on calving rate by parity.

\begin{tabular}{lcccc}
\hline & $\begin{array}{l}\text { First } \\
\text { lactation }\end{array}$ & $\begin{array}{l}\text { Second } \\
\text { lactation }\end{array}$ & $\begin{array}{l}\text { Third } \\
\text { lactation }\end{array}$ & $\begin{array}{l}\text { Fourth } \\
\text { lactation }\end{array}$ \\
\hline Number of records (cows) & 26876 & 20723 & 13229 & 15585 \\
Mean calving rate & 0.40 & 0.35 & 0.34 & 0.30 \\
Standard deviation & 0.49 & 0.48 & 0.47 & 0.46 \\
Using inbreeding of the dam & & & & \\
Average F(x) & 3.68 & 3.42 & 3.14 & 2.41 \\
Standard deviation F(x) & 2.35 & 2.33 & 2.33 & 2.23 \\
Inbreeding depression/1\% F(x) & -0.004 & -0.004 & -0.006 & -0.001 \\
Standard error & 0.001 & 0.001 & 0.002 & 0.002 \\
$P$-value & 0.004 & 0.009 & 0.001 & 0.686 \\
Heritability & 0.01 & 0.01 & 0.02 & 0.02 \\
Using inbreeding of the fetus & & & & 3.77 \\
Average F(x) & 4.65 & 4.46 & 4.26 & 2.04 \\
Standard deviation F(x) & 2.19 & 2.16 & 2.09 & +0.002 \\
Inbreeding depression/1\% F(x) & -0.004 & -0.001 & -0.005 & 0.002 \\
Standard error & 0.001 & 0.002 & 0.002 & 0.306 \\
$P$-value & 0.002 & 0.423 & 0.006 & 0.02 \\
Heritability & 0.01 & 0.01 & 0.02 & \\
\hline
\end{tabular}

inbreeding across parities in Table 1. Inbreeding depression was not significant $(P<0.01)$ in second through fourth parities, but would have been declared significant for fourth parity at $(P<0.05)$. For Jerseys, the effects of inbreeding on fertility were greater in younger animals, a result consistent with Thompson et al. (2000b) for test-day milk production in Jerseys. Perhaps some of the inbred Jerseys that express depression in fertility do not survive commercial culling pressure to have two or more calves. We did not observe such an effect in Holsteins, however.

Fertility to first inseminations verified by a subsequent calving, CR, was evaluated on cows bred in 1995 to 1996. Results are shown in Table 4 for Holsteins and Table 5 for Jerseys. Tables 4 and 5 report effects of both maternal and fetal inbreeding on CR in both breeds, from separate analysis. We did not fit both effects simul- taneously, preventing detection of interaction or changes in the magnitude of maternal and fetal inbreeding if fit jointly. However, the small and frequently nonsignificant independent effects of maternal and fetal inbreeding did not support consideration of a more complex model.

Average inbreeding in Holstein cows in Table 4 again declined as parity increased. Fetal inbreeding also declined for later parities. Pulkkinen et al. (1997) observed fetal inbreeding to increase as dam's inbreeding decreased in Dutch Holsteins, but that study partitioned cows and the fetus they carried by inbreeding rather than by parity. Perhaps producers were more aware of inbreeding considerations in choosing mates for inbred cows. The CR declined with advancing parity in Holsteins. The CR was 0.15 lower than 70d NR in first-parity cows, suggesting embryonic losses later in

Table 5. Effects of inbreeding in Jersey cows or in the fetus on calving rate by parity.

\begin{tabular}{lcccc} 
& $\begin{array}{l}\text { First } \\
\text { lactation }\end{array}$ & $\begin{array}{l}\text { Second } \\
\text { lactation }\end{array}$ & $\begin{array}{l}\text { Third } \\
\text { lactation }\end{array}$ & $\begin{array}{l}\text { Fourth } \\
\text { lactation }\end{array}$ \\
\hline Number of records (cows) & 11662 & 9618 & 7374 & 11742 \\
Mean calving rate & 0.45 & 0.43 & 0.41 & 0.36 \\
Standard deviation & 0.50 & 0.50 & 0.49 & 0.48 \\
Using inbreeding of the dam & & & & \\
Average F(x) & 4.62 & 4.21 & 3.83 & 3.07 \\
Standard deviation F(x) & 2.79 & 2.70 & 2.52 & 2.66 \\
Inbreeding depression/1\% F(x) & -0.006 & -0.004 & -0.003 & -0.003 \\
Standard error & 0.002 & 0.002 & 0.002 & 0.002 \\
$P$-value & 0.001 & 0.024 & 0.164 & 0.121 \\
Heritability & $<0.01$ & 0.06 & 0.01 & 0.02 \\
Using inbreeding of the fetus & 5.96 & & & 4.47 \\
Average F(x) & 2.89 & 5.67 & 5.28 & 2.63 \\
Standard deviation F(x) & -0.004 & +0.001 & -0.000 & +0.001 \\
Inbreeding depression/1\% F(x) & 0.002 & 0.002 & 0.002 & 0.002 \\
Standard error & 0.025 & 0.707 & 0.884 & 0.533 \\
$P$-value & 0.01 & 0.06 & 0.01 & 0.02 \\
Heritability & & & & \\
\hline
\end{tabular}


gestation. The difference increased to 0.19 by fourth parity. As with 70d NR, heritability was quite low, 1 or $2 \%$ for all parities.

Maternal inbreeding significantly depressed CR $(P<$ 0.01 ) for first, second, and third parities, but not for fourth in Holsteins. Inbreeding depression was about $4 \%$ for $10 \%$ maternal inbreeding in these Holstein cows. Fetal inbreeding depression was also undesirable and significant for first and third parities (4 or 5\% decline per $10 \%$ inbreeding), but not significant for second and fourth parities. These results suggest that maintenance of a pregnancy for an entire gestation period is affected by either maternal or fetal inbreeding, but the effect is not large for cows that calve at least once. We cannot conclude that both maternal and fetal inbreeding reduce CR, as the effects were not considered jointly.

Effects of maternal and fetal inbreeding in Jerseys on CR are in Table 5. The four datasets were the smallest used in this study. Both maternal and fetal inbreeding declined as parity advanced, consistent with other results. Mean CR was lower than mean $70 d$ NR by 0.13 to 0.17 with greater declines in later parities. Maternal inbreeding depression was significant $(P<0.01)$ for first lactation $C R$, but not for later parities, a result consistent with 70d NR. Maternal inbreeding depression for $\mathrm{CR}$ was significant for second lactation at $(P<0.05)$. The inbreeding depression observed was $6 \% / 10 \%$ increase in inbreeding, again in agreement with results for $70 \mathrm{~d} N R$ in first parity. We observed no significant fetal inbreeding depression $(P<0.01)$ in the Jersey data, although first-parity results were significant at $(P<0.05)$. Whereas more data might verify existence of fetal inbreeding depression, we could not conclude that inbreeding in the fetus was a separate effect from inbreeding in the dam, as the two effects were not fit jointly and they do appear to covary with parity.

Inbreeding depression in 70d NR from a single insemination appears to be minor, particularly for cows with relatively small inbreeding coefficients $(<10 \%)$. The largest effects of inbreeding in either 70d NR or CR occurred in first parity, either due to effects of selection, compensatory growth/development of inbred animals, or simply lack of sufficient nonadditive genetic variation for inbreeding depression to be expressed. The effects are cumulative over the lifetime of a cow, however. Further, inbreeding may depress $70 \mathrm{~d} \mathrm{NR}$ and resulting CR from second and subsequent inseminations as well. Our results are confirming evidence of the findings of Smith et al. (1998) that inbreeding extends first calving interval and extension of days open reported by Hoeschele (1991). Our results also confirm that the effects of inbreeding are not dramatic.

\section{CONCLUSIONS}

Effects of inbreeding on 70d NR and CR are small, consistently undesirable, but not consistently significant in Holstein and Jersey data when analyzed by a repeatability model or separately for parities 1 through 4. Additive variance is a small portion of total variation in these two traits with heritabilities of 1 or $2 \%$ in almost all analyses. Inbreeding depression in a fertility trait measured on one insemination does understate the cumulative effect of inbreeding depression in fertility on total lifetime merit of the dairy cow. However, we find no evidence of a dramatic effect of inbreeding on the two reproductive parameters included in this study.

Our estimates of inbreeding depression are from field data where highly inbred cows are rare. Thus, the results apply primarily to cows with little inbreeding. Linearity of inbreeding depression in more highly inbred cows may not be a correct extrapolation of these results. Genetic variation, either additive or nonadditive, is a small part of total variation for fertility traits and the cows with phenotypes available are not highly inbred. Small, undesirable, but not consistently significant results seem reasonable in light of these conditions.

\section{ACKNOWLEDGMENTS}

We wish to thank Holstein Association, USA, and the American Jersey Cattle Association for financial support, DRMS Raleigh and John Clay for phenotypic information, and the staff of AIPL, USDA for pedigree data necessary to conduct this study.

\section{REFERENCES}

Animal Improvement Programs Laboratory. 2003. AIPL inbreeding coefficients for Holstein and Jersey cows. http://aipl.arsusda.gov/ dynamic/inbrd/current/kindx.html. Accessed Feb. 14, 2003.

Boldman, K. G., L. A. Kriese, L. D. Van Vleck, C. P. Van Tassell, and S. D. Kachman. 1995. A manual for use of MTDFREML. A set of programs to obtain estimates of variances and covariances. [Draft], USDA-ARS, Lincoln, NE.

Cassell, B. G., V. Adamec, and R. E. Pearson. 2003. Effect of incomplete pedigrees on estimates of inbreeding and inbreeding depression for days to first service and summit milk yield in Holsteins and Jerseys. J. Dairy Sci. 86:2986-2995.

Golden, B. L., W. M. Snelling, and C. H. Mallinckrodt. 1995. Animal Breeder's Tool Kit 2.0. User's Guide and Reference Manual. Department of Animal Sciences, Colorado State University, Ft. Collins.

Hoeschele, I. 1991. Additive and nonadditive genetic variance in female fertility of Holsteins. J. Dairy Sci. 74:1743-1752.

Nebel, R. L., J. H. Bame, and R. E. Pearson. 2002. Factors affecting the intensity and duration of estrus of Holstein and Jersey cattle. J. Dairy Sci. 85(Suppl. 1):266. (Abstr.)

Notter, D. R. 1999. The importance of genetic diversity in livestock populations of the future. J. Anim. Sci. 70:1060-1067.

Pulkkinen, T. I., T. van der Lende, A. F. Groen, L. M. T. E. Kaal, and J. J. Zonderland. 1997. The effect of inbreeding on components of 
dairy cattle fertility as calculated from non-return data, using a multiphasic logistic function. Interbull Bull. 18:74-77.

Smith, L. A., B. G. Cassell, and R. E. Pearson. 1998. The effects of inbreeding on the lifetime performance of dairy cattle. J. Dairy Sci. 81:2729-2737.

Thompson, J. R., R. W. Everett, and N. L. Hammerschmidt. 2000a. Effects of inbreeding on production and survival in Holsteins. J. Dairy Sci. 83:1856-1864.
Thompson, J. R., R. W. Everett, and C. W. Wolfe. 2000b. Effects of inbreeding on production and survival in Jerseys. J. Dairy Sci. 83:2131-2138.

VanRaden, P. M. 1992. Accounting for inbreeding and crossbreeding in genetic evaluation of large populations. J. Dairy Sci. 75:3136-3144

Weigel, K. A., and R. Rekaya. 2000. Genetic parameters for reproductive traits of Holstein cattle in California and Minnesota. J. Dairy Sci. 83:1072-1080. 